\title{
The Potentiostatic Etching Figures of Cold-Rolled Austenitic Stainless Steels*
}

\author{
By Nobuo Nakajima**, Tatsuo Maekawa** Sadayoshi Nagata** \\ and Masaru Kagawa**
}

\begin{abstract}
The potentiostatic etching technique for austenitic stainless steels was studied to observe changes in the microstructures by cold-rolling. The etching potentials of each phase (ferrite, austenite and grain boundaries) were determined from the etching figures of an annealed AISI $321 \mathrm{~L}$ stainless steel. $1 \mathrm{~N} \mathrm{H}_{2} \mathrm{SO}_{4}$ (containing $0.01 \mathrm{~g} / \mathrm{L} \mathrm{NH} \mathrm{NCN}_{4}$ ) and conc $\mathrm{HNO}_{3}$ were selected as etching solutions. The $\alpha$-ferrite phase caused by cold-rolling was etched at a potential of -0.35 (V vs S.C.E) in $\mathrm{H}_{2} \mathrm{SO}_{4}$, and the distribution of the ferrite phase was observed by an electron microscope. The slipping bands were etched at $-0.2 \mathrm{~V}$ that corresponds to the etching potential of austenite phase. The grain boundaries were etched at $1.2 \mathrm{~V}$ in conc $\mathrm{HNO}_{3}$, and deformation of the grains by cold-rolling was observed.
\end{abstract}

(Received September 21, 1965)

\section{Introduction}

It is well known that the austenitic stainless steel has a tendency to precipitate a ferrite or martensitic phase by cold-working, which affects its corrosion properties (1) (3). A detailed study of the microstructure of the cold-worked stainless steel is very important in the study of corrosion processes. Usually the structures of the metals and alloys are studied by metallographic techniques which make use of the differential etching properties of the individual phase in identification, and many etching reagents have been proposed for microscopic examination of stainless steels ${ }^{(4)}$. However, the selective etching of the individual phases in cold-worked stainless steel is very difficult by a usual chemical or electrical etching technique, because the etching properties of the precipitated phases by cold-working is quite similar to those of the matrix, and that slipping bands of the matrix have a property to be etched easily in the etching reagents. workers ${ }^{(5) \sim(8)}$ have studied the potentiostatic etching techniques for stainless steels and reported the etching conditions for $\alpha, \gamma, \delta$ and $\sigma$ phases in annealed stainless steels, but little has been dealt with the potentiostatic etching technique for cold-worked stainless steels. The investigation reported here was undertaken to study the potentiostatic etching technique for etching of the coldworked stainless steels and to observe the microstructure of the cold-rolled stainless steels of AISl Type 304 and 304 L.

\section{Experimental Method}

\section{Specimens}

Three typical types of stainless steels were selected from commercial stainless steels for this study. Their chemical compositions are shown in Table 1 . The stainless steel of AISI Type $321 \mathrm{~L}$ containing the $\delta$-ferrite phase in an annealed state. This steel is useful as a reference material to determine the etching condition of

Table 1 Chemical compositions of specimens used.

\begin{tabular}{|c|c|c|c|c|c|c|c|c|c|c|}
\hline \multirow{2}{*}{ Specimen } & \multicolumn{10}{|c|}{ Chemical composition (wt $\%$ ) } \\
\hline & C & $\mathrm{Si}$ & Mn & $\mathbf{P}$ & $\mathbf{S}$ & $\mathrm{Cu}$ & $\mathrm{Ni}$ & $\operatorname{Cr}$ & $\mathrm{Ti}$ & $\mathbf{N}$ \\
\hline $304 \mathrm{~L}$ & 0.018 & 0.27 & 1.26 & 0.012 & 0.014 & 0.01 & 9.87 & 18.65 & - & 0.017 \\
\hline 304 & 0.045 & 0.47 & 1.55 & 0.021 & 0.007 & 0.07 & 13.10 & 18.05 & - & 0.020 \\
\hline $321 \mathrm{~L}$ & 0.025 & 0.98 & 1.84 & 0.010 & 0.011 & 0.03 & 9.11 & 20.16 & 0.24 & - \\
\hline
\end{tabular}

Recently a potentiostatic etching method, under a suitable selected potential for a given phase, is becoming one of the most useful techniques for selective etching of a material having several phases. Several

* This paper was published in Japanese in the Journal of the Japan Institute of Metals, 29 (1965), 252.

** Engineering and Research Laboratory, Mitsubishi Atomic Power Industries, Incorporated, Saitama, Japan.

(1) T. Maekawa, M. Kagawa, N. Nakajima and S. Nagata : Trans. JIM, 5 (1964), 22.

(2) T. Maekawa, M. Kagawa and N. Nakajima : ibid, 5 (1964), 219.

(3) H. H. Uhlig: Corrosion, 7 (1963), 231 t.

(4) ASTM Standard, E 3-62 (1962). the ferrite phase. The AISI Type 304 stainless steel selected for this study contains no ferrite phase in both annealed and cold-worked states. On the other hand, the AISI Type 304 L stainless steel selected for this study contains no ferrite phase in the annealed state, but contains a great deal of the $\alpha$-ferrite phase in the coldworked state. The ferrite contents measured by an $\mathrm{X}$-ray diffraction technique ${ }^{(1)}$ are shown in Table 2.

These stainless steels were solution treated in hydro-

(5) V. Cihal and M. Prazak: J. Iron Steel Inst., 193 (1959), 360.

(6) C. Edeleanu: ibid, 185 (1957), 482.

(7) N. Ito and G. Okamoto: Trans. JIM, $2(1961), 120$.

(8) F. K. Naumann: Arch. Eisenhütt , 34 (1963), 187. 
gen atmosphere at $1050^{\circ} \mathrm{C}$ for 30 minutes, and waterquenched. The 304 and $304 \mathrm{~L}$ stainless steels were cold-rolled by $20 \sim 80 \%$. The surfaces of the specimens were abraded with 1000-grit paper, and electropolished in a $\mathrm{H}_{3} \mathrm{PO}_{4}-\mathrm{H}_{2} \mathrm{SO}_{4}$ bath to avoid the effect of the

Table 2 Ferrite contents in cold-rolled specimens by $\mathrm{X}$-ray analysis.

\begin{tabular}{c|c|c|c|c}
\hline Degree of cold work & \multicolumn{4}{|c}{ Ferrite content (\%) } \\
\hline Specimen & 0 & 20 & 40 & 80 \\
\hline $321 \mathrm{~L}$ & 1 & - & - & - \\
$304 \mathrm{~L}$ & 0 & 8.8 & 11.7 & 33.5 \\
304 & 0 & 0 & 0 & 0 \\
\hline
\end{tabular}

\section{Etched figures of annealed 321L stainless steel}

Since the specimen contains the $\delta$-ferrite phase even under the annealed state, it is useful as a reference material in determining the etching condition of ferrite phase in the austenite matrix. The figures etched at $-0.35,-0.2,1.2$ and $1.4 \mathrm{~V}$ in $1 \mathrm{~N} \mathrm{H}_{2} \mathrm{SO}_{4}$ containing $0.01 \mathrm{~g} / \mathrm{L} \mathrm{NH}_{4} \mathrm{SCN}$ are shown in Photo. 1. The etching figure at $-0.35 \mathrm{~V}$ indicates a preferential attacking in the $\delta$-ferrite phase. The etching figure at $-0.2 \mathrm{~V}$ indicates a preferential attacking in the austenite matrix, which is a reverse figure to that etched at $-0.35 \mathrm{~V}$. The etching figures at 1.2 and $1.4 \mathrm{~V}$ indicate attackings in the $\delta$-ferrite phase and grain boundaries, and it is difficult to etch the each phases separately. These results

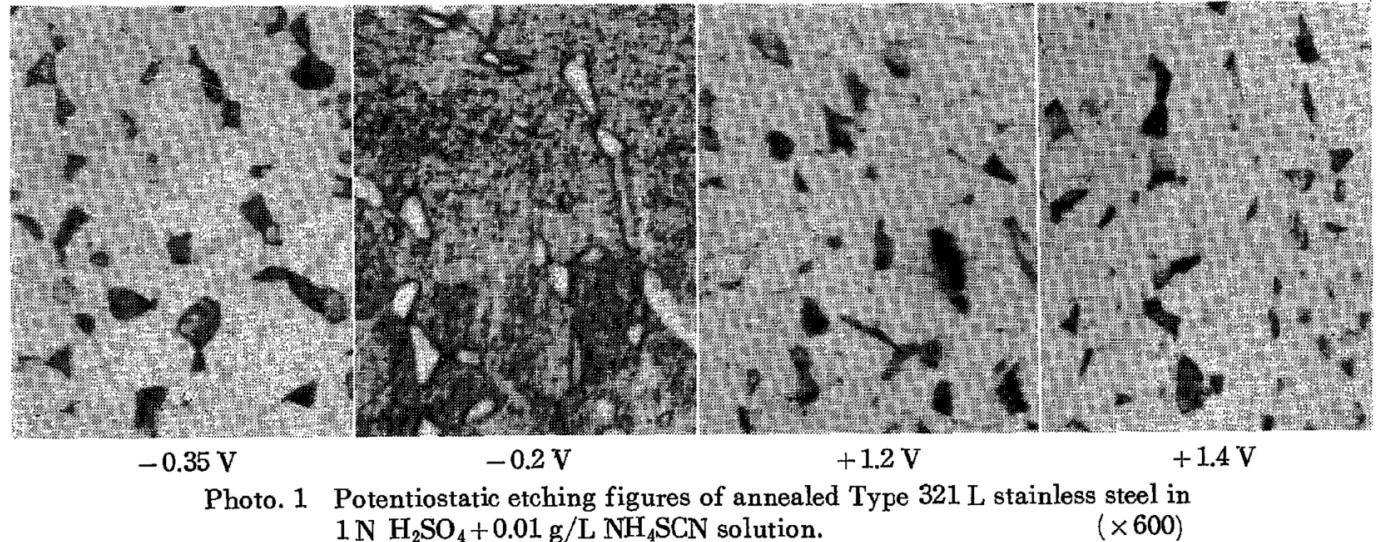

abrading.

\section{Observation of etching figures}

Two solutions of $1 \mathrm{~N} \mathrm{H}_{2} \mathrm{SO}_{4}$ containing $0.01 \mathrm{~g} / \mathrm{L}$ $\mathrm{NH}_{4} \mathrm{SCN}$ and conc $\mathrm{HNO}_{3}$ were selected as electrolytes. The etching potentials selected from the available data (5) $\sim$ (7) were $-0.35,-0.2,1.2$ and $1.4 \mathrm{~V}$ (vs S.C.E.). Etchings were carried out at room temperature. Prior to the etching in the active region, the surface of the specimen was activated in the etching solution at $-1.0 \mathrm{~V}$ (vs S.C.E.) for few minutes. Since the etching rates of the specimens varied over a wide range, the optimum etching time was determined individually from the observation of each etched figure by an optical microscope. The etched surfaces were observed by optical and electron microscopes. The replica films for electron microscopic observation were prepared by a two-stage acetyl cellulose-carbon method and were shadowed by metallic chromium at an angle of 45 degrees.

\section{Observation of thin foils by transmission electron microscopy}

Typical specimens were electropolished to thin foils by a "Window" technique, and direct observations of the microstructure by a transmission electron microscope were made. Furthermore, some foils were etched potentiostatically, and the direct observations were made again to observe the etched structure at the setting potential. The typical positions on the foils were identified by a limited area diffraction technique.

\section{Results and Discussion}

agree with that of literature ${ }^{(5)}$.

In order to etch grain boundaries preferentially, the etching in conc $\mathrm{HNO}_{3}$ was carried out. Photo. 2 indicates the etching figure in conc $\mathrm{HNO}_{3}$ at $1.2 \mathrm{~V}$. This photograph indicates the preferential etching of grain boundaries is achieved without etching of the $\delta$-ferrite phase. This shows that the conc $\mathrm{HNO}_{3}$ is a suitable electrolyte for etching of the grain boundaries.

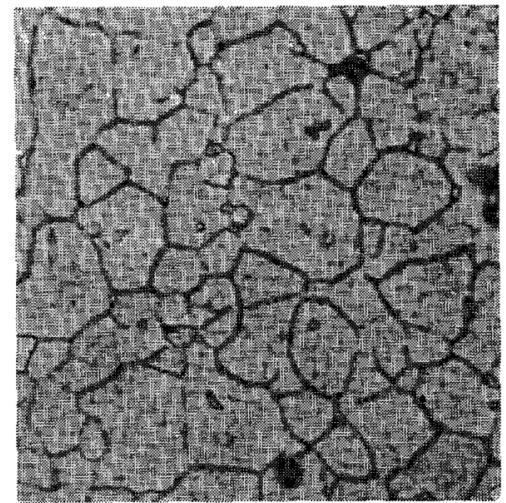

Photo. 2 Potentiostatic etching figure of annealed Type $321 \mathrm{~L}$ stainless steel in $65 \% \mathrm{HNO}_{3}$ at $1.2 \mathrm{~V}$.

$(\times 600)$

\section{Etching figures of cold-rolled stainless steels}

\section{(1) Etching figures at $\mathbf{- 0 . 3 5} \mathrm{V}$}

Photo. 3 shows a set of optical micrographs of the cold-rolled 304 and 304 L stainless steels etched in 1 $\mathrm{N} \mathrm{H}_{2} \mathrm{SO}_{4}$ containing $0.01 \mathrm{~g} / \mathrm{L} \mathrm{NH}_{4} \mathrm{SCN}$ at $-0.35 \mathrm{~V}$, the 
etching potential corresponding to that of the $\delta$-ferrite phase in the annealed $321 \mathrm{~L}$ stainless steel. Although the etchings of both steels were carried out under an equi-quantity of $0.15 \mathrm{coul} / \mathrm{cm}^{2}$, these photographs show that there is a great difference between the etched figures

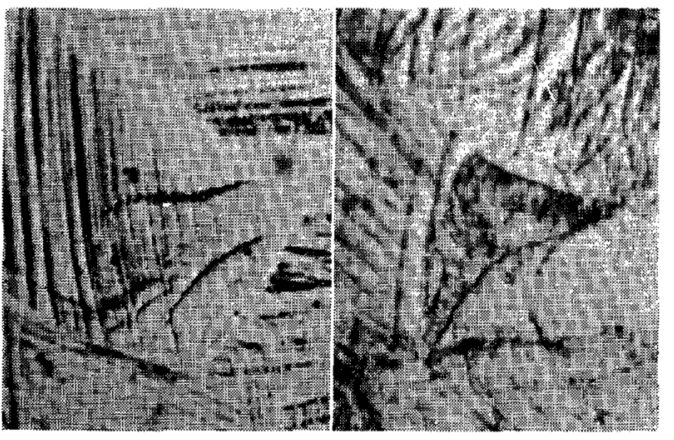

Type $304 \mathrm{~L}$ microstructures in the vicinity of the slipping bands of both steels. That is, the eleciron micrographs of the 304 L stainless steel which contains the $\alpha$-ferrite phase indicates a reticular structure, while the 304 stainless steel which contains no ferrite phase indicate only slip-

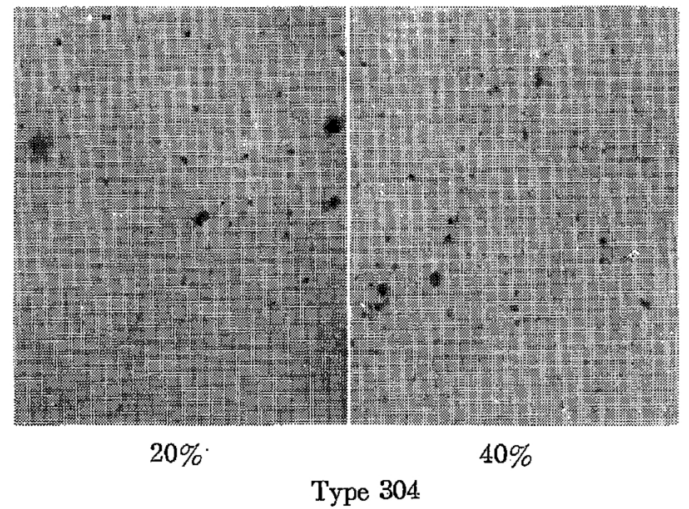

Photo. 3 Potentiostatic etching figures of cold-rolled stainless steels of Type $304 \mathrm{~L}$ and 304 in $1 \mathrm{~N}$ $\mathrm{H}_{2} \mathrm{SO}_{4}+0.01 \mathrm{~g} / \mathrm{L} \mathrm{NH} \mathrm{NCH}_{4} \mathrm{Solution}$. Each sample was etched under an equal quantity of elctricity of $0.15 \mathrm{coul} / \mathrm{cm}^{2}$ at $-0.35 \mathrm{~V}$.
$(\times 600)$

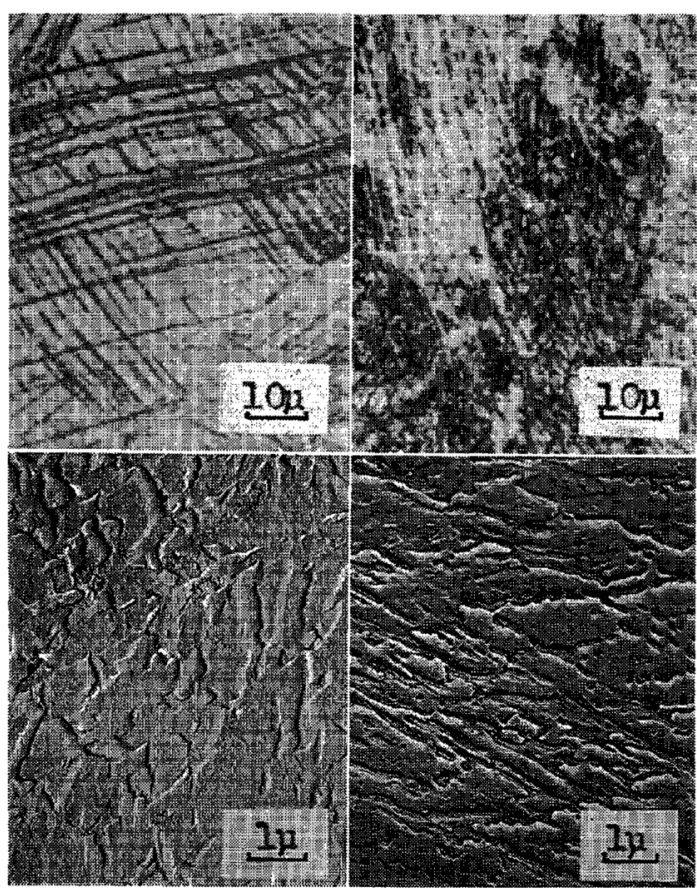

$20 \%$

$$
\text { Type } 304 \mathrm{~L}
$$

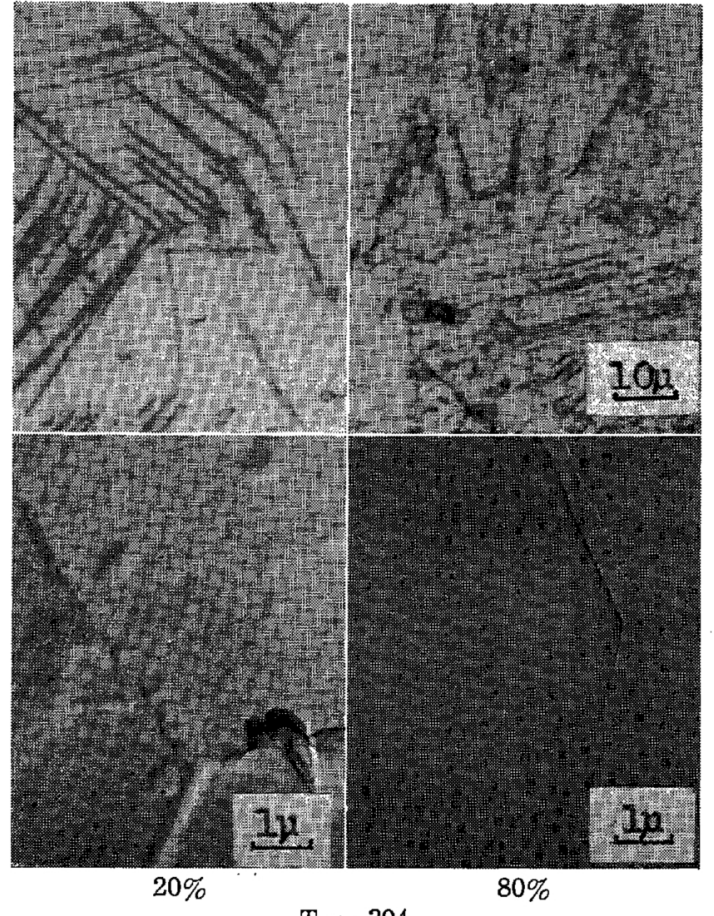

Type 304

Photo. 4 Potentiostatic etching figures of cold-rolled stainless steels of Type $304 \mathrm{~L}$ and 304 in $1 \mathrm{~N} \mathrm{H}_{2} \mathrm{SO}_{4}+0.01 \mathrm{~g} / \mathrm{L} \mathrm{NH} \mathrm{SCN}_{4}$ solution at $-0.35 \mathrm{~V}$.

of 304 and $304 \mathrm{~L}$ stainless steels. That is, the $304 \mathrm{~L}$ stainless steel which contains the $\alpha$-ferrite phase indicates a complicated figure by such a slight etching (less than 1 minute etching), while the 304 stainless steel containing no ferrite phase does not indicate such a visible figure. The figure of the 304 stainless steel becomes visible by a heavier etching (several tens of minutes etching), though it shows a different appearance from that of the 304 $\mathrm{L}$ stainless steel. Photo. 4 shows the etching figures of the cold-rolled two steels as observed by optical and electron microscopes. The optical micrographs of both steels at a low magnification seem to have figures similar to those etched along the slipping bands. However, the electron micrographs at a high magnification indicate a great difference in the ping bands or grain boundaries. The distribution fo the reticular structures in the cold-rolled 304 L stainless steel seem to be related to the density of slipping bands or the orientation of grains. The fact that the reticular structure is observed only in the cold-rolled steel containing the $\alpha$-ferrite phase, implies that the network structure represents the $\alpha$-ferrite phase precipitated by coldworking.

\section{(2) Etching figures at $-0.2 \mathrm{~V}$}

Photo. 5 shows the etching figures of the cold-rolled 304 and $304 \mathrm{~L}$ stainless steels in $1 \mathrm{~N} \mathrm{H}_{2} \mathrm{SO}_{4}$ containing $0.01 \mathrm{~g} / \mathrm{L} \mathrm{N} \mathrm{H}_{4} \mathrm{SCN}$ at $-0.2 \mathrm{~V}$, the etching potential of the austenite phase in the annealed $321 \mathrm{~L}$ stainless steel. At this potential the etching rates of both steels are 
higher than those at $-0.35 \mathrm{~V}$, and the microstructure appeares by etching of less than 1 minute. In the optical micrograph, the e:ched surfaces of both steels seem to have a structure similar to that at $-0.35 \mathrm{~V}$ etching. However, the electron micrographs of the $304 \mathrm{~L}$ stainless
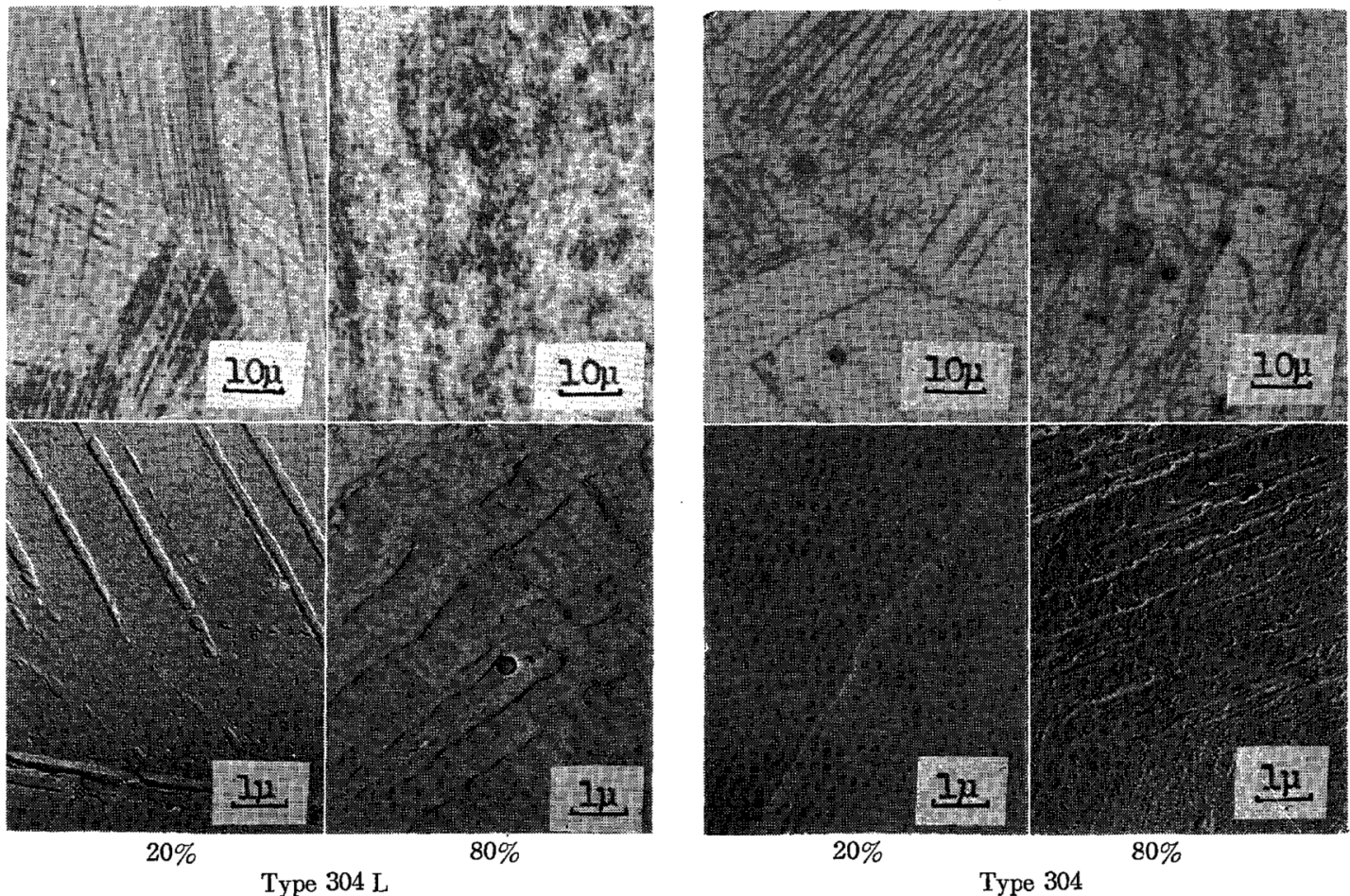

Photo. 5 Potentiostatic etching figures of cold-rolled stainless steels of Type $304 \mathrm{~L}$ and 304 in $1 \mathrm{~N} \mathrm{H}_{2} \mathrm{SO}_{4}+0.01 \mathrm{~g} / \mathrm{L} \mathrm{NH}_{4} \mathrm{SCN}$ solution at $-0.2 \mathrm{~V}$.

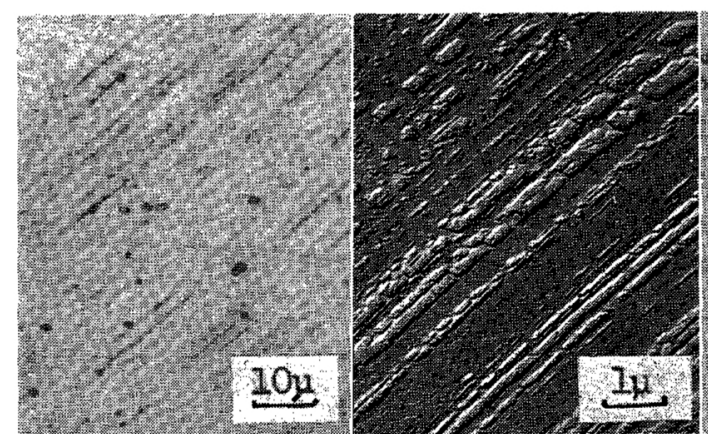

Type $304 \mathrm{~L}(20 \% \mathrm{C} . \mathrm{R}$. $)$

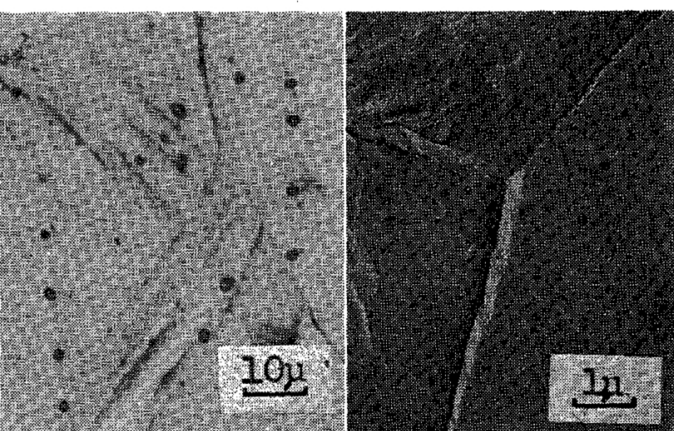

Type $304(20 \%$ C.R.)

Photo. 6 Potentiostatic etching figures of cold-rolled stainless steels of Type 304 L and 304 in $1 \mathrm{~N} \mathrm{H}_{2} \mathrm{SO}_{4}+0.01 \mathrm{~g} / \mathrm{L} \mathrm{NH}_{4} \mathrm{SCN}$ solution at $1.4 \mathrm{~V}$.

steel at a high magnification shows a difference in the etching figures at $-0.35 \mathrm{~V}$ and $-0.2 \mathrm{~V}$. As seen in Photo. 5 , the $304 \mathrm{~L}$ stainless steel does not indicate any reticular structure observed in the $-0.35 \mathrm{~V}$ etching, but shows only slipping bands. In case of the annealed $321 \mathrm{~L}$ stainless steel, the etching figure at $-0.2 \mathrm{~V}$ indicates a structure reverse to that at $-0.35 \mathrm{~V}$, but in case of the cold-rolled stainless steels such a reverse structure is not observed. This suggests that the $\alpha$ ferrite phase precipitated by cold-working have no greatly different composition from that of the austenite matrix, as compared with that of the $\delta$-ferrite phase precipitated by heat treatment. The etched figure of the cold-rolled 304 stainless steel which contains no ferrite phase indicates a structure similar to that at $-0.35 \mathrm{~V}$. ly the structures in the solution, because of every phase being attacked, and the difference between the two steels is hardly observable.

Photo. 7 shows the etching figures of the cold-rolled two steels in conc $\mathrm{HNO}_{3}$ at $1.2 \mathrm{~V}$. In this photographs, a preferential attacking in the grain boundaries can be observed, and it is also possible to observe the grain boundaries even in a specimen rolled up to $80 \%$. Photo. 8 shows a etching figure by usual electrical etching in 10\% oxalic acid. In this photograph it is observed only the fiber structure which distributes in parallel with the rolling direction, but the grain boundaries can hardly be distinguished.

In order to observe the relation between grain boundaries and slipping bands, some of the specimens were etched again in $1 \mathrm{~N} \mathrm{H}_{2} \mathrm{SO}_{4}$ containing $0.01 \mathrm{~g} / \mathrm{L} \mathrm{NH}_{4} \mathrm{SCN}$ 
at $-0.2 \mathrm{~V}$, after etching in conc $\mathrm{HNO}_{3}$ at $1.2 \mathrm{~V}$. Photo. 9 shows the etching figure of the cold-rolled 304L stainless steel. These photographs show that the slipping bands do not always correspond with the fiber structure observed by oxalic acid etching as shown in Photo. 8, is a foil as prepared by electropolishing. This photograph shows a typical structure of the cold-worked 304 L stainless steel which contains dislocations, twins and deposits, etc. Although the limited area electron diffraction of some points on the foil indicates a mixed diffrac-

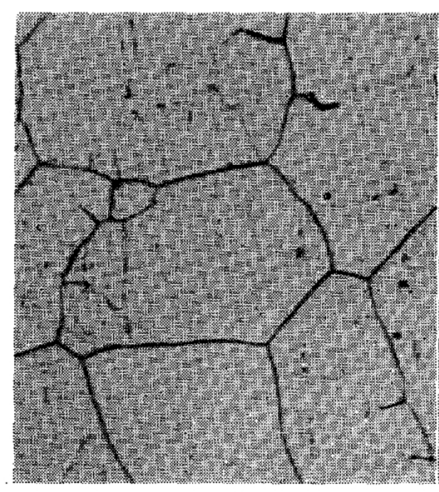

$0 \%$ Photo.

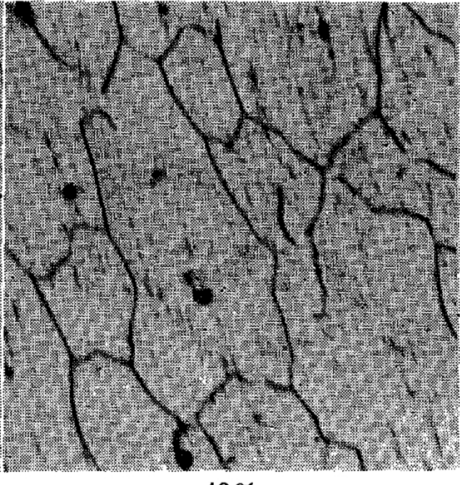

$40 \%$

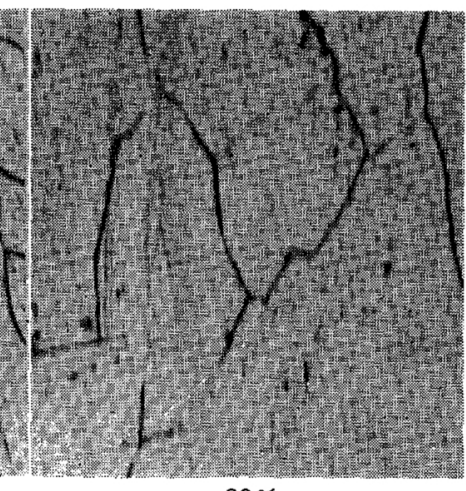

$80 \%$

Potentiostatic etching figures of cold-rolled stainless steel of 304 in $65 \% \mathrm{HNO}_{3}$ at $1.2 \mathrm{~V}$. $(\times 300)$

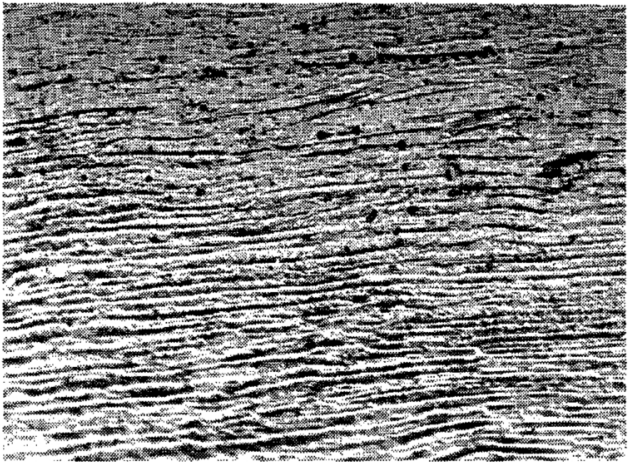

Photo. 8 Etching figure of cold-rolled (70\%) stainless steel of AISI Type $304 \mathrm{~L}$ in $10 \%$ oxalic acid solution under a constant current density of $10 \mathrm{~mA} / \mathrm{cm}^{2}$. tion pattern of austenite and ferrite, it is difficult to observe the distribution of the ferrite phase in the foil.

In order to observe the distribution of the ferrite phase, the foils were etched in $1 \mathrm{~N} \mathrm{H}_{2} \mathrm{SO}_{4}$ solution containing $0.01 \mathrm{~g} / \mathrm{L} \mathrm{NH}_{4} \mathrm{SCN}$. Photos. 11 and 12 show transmission electron micrographs of the two foils etched at -0.2 and $-0.35 \mathrm{~V}$ which are proposed as the etching potentials of the austenite and ferrite phases, respectively. These photographs indicate the characteristic structures corresponding to the etching properties of the specimen at a given potential. The transmission electron micrograph of a foil etched at $-0.35 \mathrm{~V}$ indicates a reticular structure, which is considered to correspond with that observed in Photo. 4. The limited area electron diffraction of the reticular structures always in-

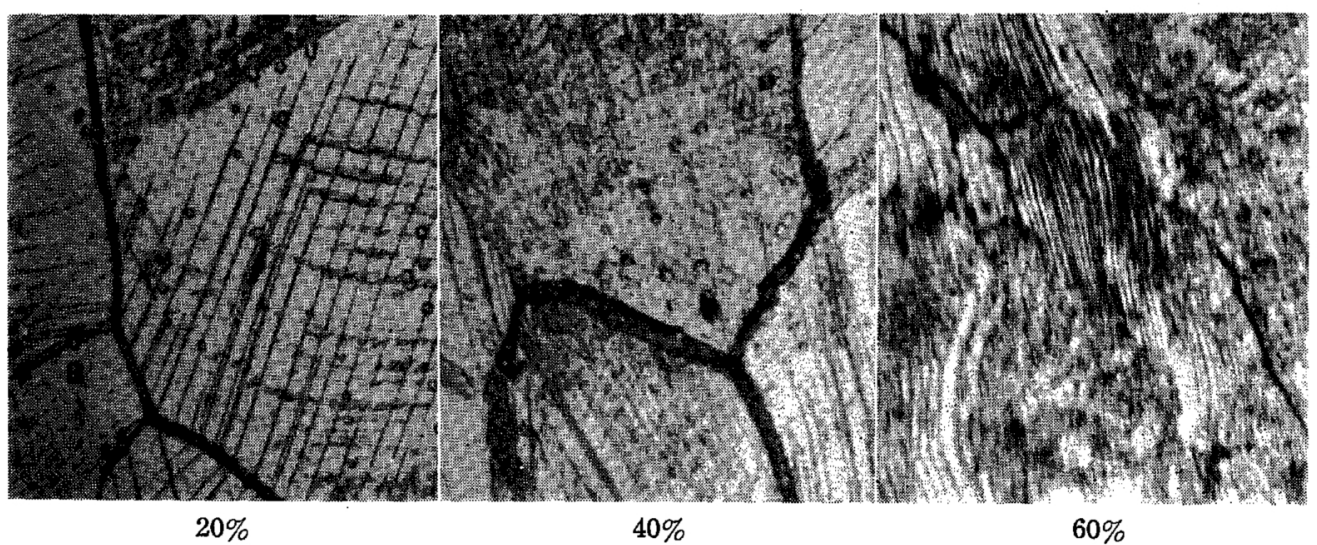

Photo. 9 Potentiostatic etching figures of cold-rolled stainless steel of $304 \mathrm{~L}$. The samples were etched in $1 \mathrm{~N} \mathrm{H}_{2} \mathrm{SO}_{4}+0.01 \mathrm{~g} / \mathrm{L} \mathrm{NH}_{4} \mathrm{SCN}$ solution at $-0.2 \mathrm{~V}$, after the etching in $65 \% \mathrm{HNO}_{3}$ at $1.2 \mathrm{~V}$.

$(\times 600)$

and affected by the orientation of grains or grain boundaries.

\section{Transmission electron microscopy of cold- rolled stainless steel}

Photos. 10 12 show the structure of thin foils of the cold-rolled 304 L stainless steel observed directly by a transmission electron microscope at an accelerated voltage of $80 \mathrm{KV}$. The specimen used for Photo. 10 dicates a mixed diffraction pattern of austenite and $\alpha$ ferrite. This suggests that the reticular structure represent the distribution of the $\alpha$-ferrite phase in the austenite matrix.

An analysis of the transmission electron micrograph of the etched foils would involve a more complicated problem and require further investigations. From the results of the present work, it can be said that the potentiostatic etching method is a useful technique to 


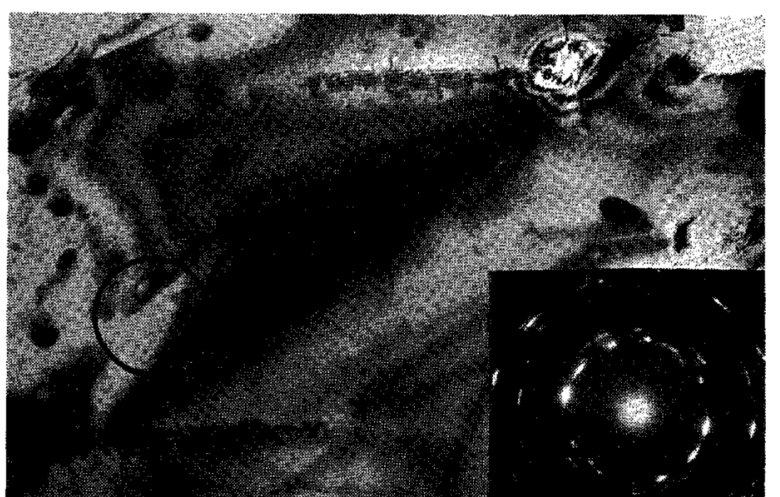

Photo. 10 Transmission electron micrograph of cold-rolled $(20 \%)$ stainless steel of AISI Type $304 \mathrm{~L}$. (as electropolished)

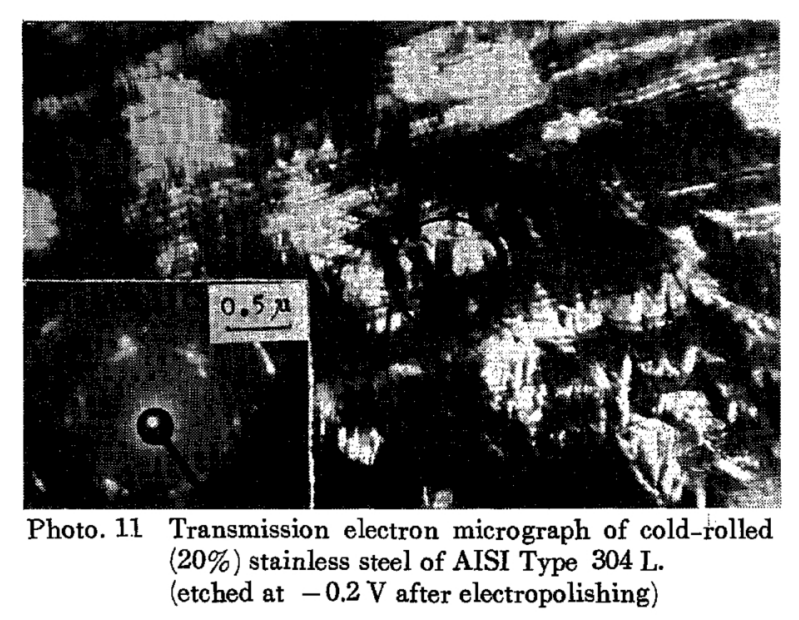

study the microstructure of metals and alloys by transmission electron microscopy.

\section{Summary}

The potentiostatic etching figures of the cold-rolled stainless steels of AISI Type 304 and 304 L were observed by optical and electron microscopes, and the

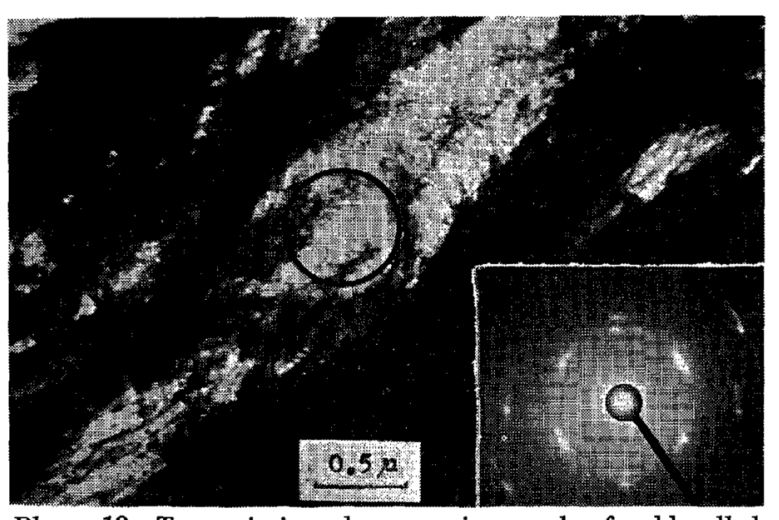

Photo. 12 Transmission electron micrograph of cold-rolled (20\%) stainless steel of AISI Type $304 \mathrm{~L}$. (etched at $-0.35 \mathrm{~V}$ after electropolishing)

etching conditions of the $\alpha$-ferrite phase, slipping bands and grain boundaries were studied. The $\alpha$-ferrite phase precipitated by cold-working was etched preferentially in $1 \mathrm{~N} \mathrm{H}_{2} \mathrm{SO}_{4}$ solution containing $0.01 \mathrm{~g} / \mathrm{L} \mathrm{NH}_{4} \mathrm{SCN}$ at $-0.35 \mathrm{~V}$ (vs S.C.E.) in a same way as the $\delta$-ferrite phase in the annealed stainless steel of AISI Type $321 \mathrm{~L}$. The microscopic observation of the coldrolled specimen indicated that the $\alpha$-ferrite phase is precipitated along slipping bands in the form of a reticular structure. The slipping bands were etched at $-0.2 \mathrm{~V}$ that corresponds to the etching potential of the austenite phase in the same solution. The grain boundaries were etched at $1.2 \mathrm{~V}$ in conc $\mathrm{HNO}_{3}$ without etching of slipping bands and ferrite phase.

\section{Acknowledgments}

The authors wish to express their sincere thanks to Dr. Masatoshi Yokosuka, Director of the Laboratory of Mitsubishi Atomic Power Industries, Inc., for permission of the present work, to Mr. Kazumu Sugimoto, Manager of the Material Research and Development Department, and to Dr. Shuichiro Takahahi, Manager of the Solid State Physics Section of the Laboratory, for their supports to this work. 